SCIENTIFIC REPORT

\title{
A pilot study on the use of a perfluorohexyloctane/silicone oil solution as a heavier than water internal tamponade agent
}

\author{
D Wong, J C Van Meurs, T Stappler, C Groenewald, I A Pearce, J N McGalliard, E Manousakis, \\ E N Herbert
}

Br J Ophthalmol 2005;89:662-665. doi: 10.1136/bjo.2004.055178

\begin{abstract}
Aims: To report a prospective two centred non-comparative interventional pilot study of a solution of perfluorohexyloctane and silicone oil (Densiron-68) as a heavier than water internal tamponade.

Methods: 42 consecutive patients were recruited. The indications include proliferative vitreoretinopathy, retinal detachments arising from inferior retinal breaks, and inability to posture.

Results: The success rate with one operation using Densiron was $81 \%$ and with further surgery $93 \%$. At the end of the study all tamponade agents were removed in $90 \%$ of patients. Visual acuity improved from mean logMAR of 1.41 (SD 0.64) to 0.94 (SD 0.57), $p=0.001$. There was little evidence of dispersion and excessive inflammation.

Conclusion: This new tamponade agent is being compared to conventional silicone oil in a prospective international randomised trial.
\end{abstract}

1: the past, we have demonstrated with an in vitro study that a solution of perfluorohexyloctane $\left(\mathrm{F}_{6} \mathrm{H}_{8}\right)$ and silicone oil with a specific gravity of $1.06 \mathrm{~g} / \mathrm{cm}^{3}$ has similar physical properties to silicone oil in terms of the shape of the bubble and thus its ability to act as an internal tamponade agent. ${ }^{1}$ This solution has since received its CE certification ("Conformite Européene," a marking indicating that product is regulated by the European Commission's health, safety, and environmental protection legislation (product directives); the number for Densiron is 0535) and is available in Europe for use as a heavier than water prolonged intraocular tamponade. The product, Densiron-68 (Fluoron Co, NeuUlm, Germany) has been selected for an international multicentred randomised trial comparing the safety and efficacy of heavier than water tamponade agent against normal silicone oil. We report the results of the pilot study which persuaded us to select Densiron-68 for this trial.

\section{METHODS}

We performed a prospective interventional non-comparative study of 42 eyes of 42 consecutive patients recruited from two centres (Liverpool and Rotterdam) between November 2002 and August 2003. The study was approved by the institutional review boards of both centres.

\section{Patients}

The inclusion criteria consisted of proliferative vitreoretinopathy (PVR), retinal detachments (RD) arising from posterior or inferior retinal breaks; and an inability of the patient to posture (table 1). In the presence of PVR, patients with superior and inferior breaks were included.

\section{Materials}

Densiron-68 is a solution of perfluorhexyloctane $\left(\mathrm{F}_{6} \mathrm{H}_{8}\right)$ and $5000 \mathrm{mPas}$ silicone oil. The interfacial tension against water at $25^{\circ} \mathrm{C}$ of this solution is $40.82 \mathrm{mN} / \mathrm{m}$; the specific gravity is $1.06 \mathrm{~g} / \mathrm{cm}^{3}$; the viscosity is $1387 \mathrm{mPas}$.

\section{Intervention}

Standard three port pars plana vitrectomy was performed in 34 patients. In the other eight patients there was silicone oil in situ; the oil was removed. Vitrectomy was combined with cataract surgery in six cases. Epiretinal membranes (ERM) were peeled in 17 cases. Relaxing retinotomies were performed in 11 patients and peripheral drainage retinotomies in seven patients. Perfluorocarbon liquids (PFCL) were used in 15 cases. PFCL was removed via fluid/air exchange before Densiron was instilled into the eye. Densiron removal was performed around 10-16 weeks after the initial surgery, through a pars plana approach using active aspiration via an 18 or 19 gauge needle. Posterior capsulotomies were performed in five cases. Patients that failed with Densiron were given further surgeries involving $\mathrm{C}_{3} \mathrm{~F}_{8}$ or conventional silicone oil.

\section{Postoperative posture}

All patients were postured supine for 3 hours postoperatively. Thereafter those patients with inferior retinal breaks confined to the inferior 4 clock hours were not required to posture; those with retinal breaks above 4 and 8 o'clock were postured lying on their sides; those with retinal breaks on both temporal and nasal side were postured alternately lying on the left and right sides. All postures were adopted for 10 14 days.

\section{Main outcome measures}

The primary study end point was anatomical re-attachment of the retina. Cases are judged successful when there was reattachment of the retina in the absence of any tamponade agent. Our secondary end point was to record the visual function and any complications arising from surgery, which might or might not be related with the use of Densiron.

The clinical record forms were designed using experience from a previous multicentred study of perfluorohexyloctane $\left(\mathrm{F}_{6} \mathrm{H}_{8}\right){ }^{2}$ In particular, all the previously observed complications were listed, such that the observer had to positively deny the presence of each complication. LogMAR visual

Abbreviations: ERM, epiretinal membranes; PFCL, perfluorocarbon liquids; PPV, pars plana vitrectomy; PVR, proliferative vitreoretinopathy; $\mathrm{RD}$, retinal detachments; $\mathrm{SiO}$, silicone oil 


\begin{tabular}{|c|c|c|c|c|c|c|c|c|c|c|}
\hline $\begin{array}{l}\text { Study } \\
\text { No }\end{array}$ & Age & Sex & Eye & $\begin{array}{l}\text { No of } \\
\text { previous } \\
\text { surgeries }\end{array}$ & $\begin{array}{l}\text { Nature of previous } \\
\text { retinal surgery }\end{array}$ & Macula status & Quadrants of RD & PVR & Initial VA & A Final VA \\
\hline 1 & 80 & $\mathrm{~F}$ & $\mathrm{R}$ & 1 & $\begin{array}{l}\text { Macular relocation + } \\
\text { phacoemulsification }\end{array}$ & on & 1 & no & 1.6 & 1.6 \\
\hline 2 & 54 & M & $\mathrm{R}$ & & & off & 4 & C-P3 & 2.4 & 0.78 \\
\hline 3 & 25 & M & $\mathrm{R}$ & 2 & Cryo/buckle, PPV/SiO & off & 2 & no & 0.48 & 0.3 \\
\hline 4 & 63 & M & $\mathrm{R}$ & 1 & $\mathrm{PPV} / \mathrm{SiO}$ & on & 2 & C-A2 & 1 & 0.78 \\
\hline 5 & 58 & $M$ & L & 1 & $\mathrm{PPV} /$ gas & off & 3 & no & 1 & 1.2 \\
\hline 6 & 76 & $\mathrm{~F}$ & L & & & off & 1 & C-P1 & 1.12 & 0.32 \\
\hline 7 & 65 & $\mathrm{~F}$ & L & 1 & Cryo/buckle & off & 3 & $C-P 1$ & 1.3 & 0.78 \\
\hline 8 & 80 & $\mathrm{~F}$ & $\mathrm{R}$ & & & off & 2 & C-P2 & 2.1 & 0.78 \\
\hline 9 & 57 & $\mathrm{~F}$ & $\mathrm{R}$ & & & off & 3 & no & 1.12 & 1.2 \\
\hline 10 & 83 & $\mathrm{~F}$ & $\mathrm{R}$ & & & off & 3 & C-P2 & 2.1 & 0.3 \\
\hline 11 & 39 & M & L & & & off & 2 & no & 0.78 & 0.16 \\
\hline 12 & 71 & $\mathrm{~F}$ & $\mathrm{R}$ & & & off & 2 & C-P1 & 2.4 & 0.3 \\
\hline 13 & 83 & $\mathrm{~F}$ & $\mathrm{R}$ & & & off & 4 & no & 2.4 & deceased \\
\hline 14 & 80 & $\mathrm{~F}$ & L & 1 & $\mathrm{PPV} / \mathrm{SiO}$ & on & 2 & $\mathrm{C}-\mathrm{A} 3$ & 0.78 & 0.78 \\
\hline 15 & 61 & M & L & 2 & $\mathrm{PPV} / \mathrm{SiO}, \mathrm{ROO}$ & on & 2 & $\mathrm{C}-\mathrm{A} 2$ & 0.78 & 0.6 \\
\hline 16 & 51 & $\mathrm{~F}$ & $\mathrm{R}$ & 1 & $\mathrm{PPV} / \mathrm{SiO}$ & on & 2 & C-P1 & 1.2 & 0.78 \\
\hline 17 & 57 & M & $\mathrm{R}$ & 3 & Cryo/buckle, PPV/gas, PPV/SiO & on & 1 & C-P2 & 1 & 1 \\
\hline 18 & 53 & M & $\mathrm{R}$ & 1 & Cryo/buckle & off & 3 & C-P1 & 1 & 0.78 \\
\hline 19 & 50 & $\mathrm{~F}$ & L & 2 & Cryo/buckle $\times 2$ & off & 3 & PVR B & 1 & 2.4 \\
\hline 20 & 79 & M & $\mathrm{R}$ & & & off & 2 & $C-P 1$ & 2.1 & 2.4 \\
\hline 21 & 73 & $\mathrm{~F}$ & $\mathrm{R}$ & 1 & $\mathrm{PPV} / \mathrm{SiO}$ & off & 3 & no & 1.2 & 1 \\
\hline 22 & 33 & $\mathrm{~F}$ & $\mathrm{R}$ & 1 & Cryo/buckle & off & 3 & C-P2 & 0.78 & 0.3 \\
\hline 23 & 42 & M & $\mathrm{R}$ & & & off & 4 & $C-A 2$ & 2.4 & 1 \\
\hline 24 & 27 & $\mathrm{~F}$ & L & & & off & 3 & C-A4 & 1.3 & 1.3 \\
\hline 25 & 56 & M & $\mathrm{R}$ & & & off & 4 & PVR A & 1 & 0.32 \\
\hline 26 & 64 & M & $\mathrm{R}$ & & & off & 4 & C-P1 & 1.2 & 0.78 \\
\hline 27 & 63 & M & L & & & off & 3 & no & 0.78 & 0.48 \\
\hline 28 & 63 & M & $\mathrm{L}$ & & & off & 2 & PVR B & 1 & 0.6 \\
\hline 29 & 32 & $\mathrm{~F}$ & $\mathrm{R}$ & 1 & PPV/gas & on & 2 & no & 0.48 & 0.6 \\
\hline 30 & 39 & $\mathrm{~F}$ & $\mathrm{~L}$ & 1 & Cryo/buckle & on & 2 & no & 0.16 & 0.6 \\
\hline 31 & 47 & M & $\mathrm{L}$ & 1 & Cryo/buckle & off & 2 & C-P2 & 1 & 1.6 \\
\hline 32 & 70 & M & $\mathrm{R}$ & 2 & $\mathrm{PPV} /$ gas, PPV/SiO & off & 2 & C-P1 & 1.2 & 0.6 \\
\hline 33 & 51 & M & $\mathrm{R}$ & 2 & $\mathrm{PPV} /$ gas, PPV/SiO & on & 2 & C-P2 & 1.6 & 2.4 \\
\hline 34 & 74 & M & $\mathrm{R}$ & 1 & $\mathrm{PPV} / \mathrm{SiO}$ & off & 4 & C-Al & 1.6 & 0.8 \\
\hline 35 & 69 & $\mathrm{~F}$ & $\mathrm{R}$ & 2 & Buckle, PPV/gas & off & 3 & $C-P 2$ & 1.6 & 1.6 \\
\hline 36 & 66 & $\mathrm{~F}$ & $\mathrm{~L}$ & 2 & Buckle, PPV/gas & off & 2 & C-P1 & 1.3 & 0.4 \\
\hline 37 & 31 & M & L & 1 & $\mathrm{PPV} / \mathrm{SiO}$ & off & 4 & $C-P 2$ & 1.6 & 0.6 \\
\hline 38 & 44 & $\mathrm{~F}$ & $\mathrm{R}$ & 2 & Buckle, PPV/gas & off & 2 & C-P2 & 1.9 & 1.3 \\
\hline 39 & 58 & M & L & 1 & Buckle & off & 4 & $\mathrm{C}-\mathrm{Al}$ & 1.6 & 1 \\
\hline 40 & 44 & M & $\mathrm{L}$ & 1 & Buckle & off & 4 & C-P1 & 1.3 & 1 \\
\hline 41 & 66 & $\mathrm{~F}$ & $\mathrm{R}$ & 2 & $\mathrm{PPV} /$ gas, $\mathrm{PPV} / \mathrm{SiO}$ & off & 3 & $\mathrm{C}-\mathrm{Al}$ & 1.6 & 1 \\
\hline 42 & 78 & M & $\mathrm{R}$ & 1 & $\mathrm{PPV} /$ gas & off & 2 & $C-P 1$ & 0.8 & 1 \\
\hline
\end{tabular}

acuity was obtained. Pinhole vision was recorded at each follow up visit. Fundus photography was performed on two separate occasions and was supplemented by retinal drawings. All Rotterdam patients had the surgery recorded on video.

The study design consisted of a minimum of eight visits: preoperative assessment, at operation with Densiron, l week and 1 month postoperatively; after removal of Densiron we examined the patients at 1 week, 1 month, and 3 months, postoperatively. All unscheduled appointments or additional interventions were documented.

\section{RESULTS}

A total of 42 eyes of 42 patients ( 22 males) were included in our study. The mean age was 58.45 years (SD 16.27). Twenty six patients $(61.9 \%)$ had previous RD repair. These included 14 previous scleral buckling procedures and 19 vitrectomies. In 13 cases conventional silicone oil had been used, in eight of the 13 silicone oil was still in situ at the time of presentation. Gas tamponade was previously employed in 10 of the 19 cases. The mean number of previous RD operations was 1.36 (SD 0.62) (range 1-3). At baseline one patient was aphakic, 21 were phakic, 20 were pseudophakic

Table 2 Outcome of patients with recurrent RD

\begin{tabular}{|c|c|c|c|c|c|}
\hline & Study No & $\begin{array}{l}\text { Time after } \\
\text { surgery }\end{array}$ & Treatment & $\begin{array}{l}\text { Long term } \\
\text { tamponade }\end{array}$ & $\begin{array}{l}\text { Retinal status at final } \\
\text { follow up }\end{array}$ \\
\hline \multirow{4}{*}{$\begin{array}{l}\text { RD with Densiron } \\
\text { in situ }\end{array}$} & 14 & 5 months & 5000 mPAS SiO & $\mathrm{SiO}$ in situ & Attached \\
\hline & 24 & 12 days & 5000 mPAS SiO & removed & Attached \\
\hline & 25 & 11 days & $\mathrm{C}_{3} \mathrm{~F}_{8}$ & none & Attached \\
\hline & 35 & 9 months & 5000 mPAS SiO & $\mathrm{SiO}$ in situ & Rigid inferior RD \\
\hline \multirow[t]{4}{*}{ RD after Densiron removal } & 18 & 18 days & 5000 mPAS SiO & $\mathrm{SiO}$ in situ & Attached \\
\hline & 26 & 03 days & 5000 mPAS SiO & $\mathrm{SiO}$ in situ & Attached \\
\hline & 32 & 13 days & $\mathrm{C}_{3} \mathrm{~F}_{8}$ & none & Attached \\
\hline & 33 & 3 months & Planned & none & Residual subretinal fluid \\
\hline
\end{tabular}


Table 3 Number of patients with raised IOP

\begin{tabular}{llllll}
\hline Raised IOP & $\begin{array}{l}1 \text { Week } \\
\text { postop }\end{array}$ & $\begin{array}{l}1 \text { Month } \\
\text { postop }\end{array}$ & $\begin{array}{l}1 \text { Week } \\
\text { post-ROD }\end{array}$ & $\begin{array}{l}1 \text { Month } \\
\text { post-ROD }\end{array}$ & $\begin{array}{l}3 \text { Months } \\
\text { post-ROD }\end{array}$ \\
\hline IOP $>21$ & 17 & 10 & 7 & 5 & 2 \\
IOP $>30$ & 6 & 6 & 2 & 2 & 2 \\
\hline
\end{tabular}

Postop, postoperatively; ROD: removal of Densiron.

( 16 had a posterior chamber IOL; three had an AC IOL; one had an iris claw lens).

The indication for surgery consisted of 25 inferior retinal breaks (five without PVR); one inferior giant retinal tear; 33 cases of PVR; one combined rhegmatogenous RD and choroidal detachment; two patients who were unable to posture (table 1). The number of quadrants of RD was 2.64 (SD 0.9) and the macula was detached in 32 cases (76.2\%). The mean duration of Densiron left in situ was 72 days (SD 24.8 days ).

\section{Anatomical results}

At surgery, complete re-attachment was achieved in all cases. At follow up, four of 32 patients had RD (in the superior fundus) with Densiron in situ and four developed redetachment after removal of Densiron (table 2). All patients were treated successfully with further surgery involving conventional silicone in four (for diffuse PVR in the superior fundus) and $\mathrm{C}_{3} \mathrm{~F}_{8}$ in two patients. No patients developed macular detachment after Densiron was used. At the last follow up the total retinal reattachment was achieved in 39 of 42 patients including one who had a small stable peripheral RD (no tamponade); all patients had Densiron removed and the four patients who had conventional silicone in situ are awaiting removal.

\section{Functional results}

Visual acuity improved from mean logMAR of 1.41 (SD 0.64) to a mean of 0.94 (SD 0.57). The difference in significant using a two tailed paired $t$ test; $\mathrm{p}=0.001$. The preoperative and postoperative visions of individual patients are given in table 1 . The vision improved in 27 of 41 patients $(66 \%)$, we excluded the one patient who was dead. The final logMAR vision was 1 (Snellen equivalent $6 / 60$ ) or better in $76 \%$; $\log$ MAR of 0.6 (Snellen $6 / 24$ ) or better in $37 \%$, and logMAR of 0.3 (Snellen $6 / 12$ ) or better in $22 \%$.

\section{Complications}

One patient aged 83 died suddenly from unrelated medical problems 10 weeks into the study.

\section{Cataract formation}

Of the 21 phakic eyes at baseline, two had pre-existing nuclear cataracts, four had early nuclear, and five had early cortical lens opacities. Ten patients had their cataracts removed: six at the time of Densiron injection; one at the time of Densiron removal. Posterior subcapsular changes were observed in the early postoperative period similar to that observed with conventional silicone oil. All patients who remained phakic at the last follow up had some nuclear sclerosis.

\section{Raised IOP}

The mean baseline IOP was 17.8 (SD 8.86) $\mathrm{mm} \mathrm{Hg}$. Preoperatively, five patients had pre-existing medically controlled glaucoma. At 1 week and 1 month after heavy oil operation six patients presented with an IOP higher than $30 \mathrm{~mm} \mathrm{Hg}$ and at study end 3 months after oil removal three patients had raised IOP higher than $30 \mathrm{~mm} \mathrm{Hg}$ (table 3). All cases of IOP increase were successfully treated medically. We did not observe a pupil block mechanism in this series of patients.

\section{Intraocular inflammation}

Three patients presented with a moderate AC inflammatory activity (++ out of a maximum of ++++$)$ at 1 week after the initial operation.

\section{Dispersion of Densiron}

Minor dispersion was detected postoperatively in three patients at 1 week and six patients at 1 month. This takes the form of a few droplets adherent to the posterior capsule in three patients and/or in the inferior part of the AC in three patients. We did not find any retrolental membrane or ERM which we observed with $\mathrm{F}_{6} \mathrm{H}_{8}$ use in the past.

\section{DISCUSSION}

In the past, many have argued for the need and possible indications for tamponade agents that sink. ${ }^{2-7}$ We have demonstrated in an in vitro model that it is not always feasible to achieve a total tamponade effect by completely filling the vitreous cavity: the main reason being that the eye is a near spherical cavity and geometry dictates that a slight under-fill would lead to a large area of the retina unsupported. ${ }^{8}$ The logical inference is that tamponade agents that float would be more effective at making contact with the superior fundus and heavier than water tamponade agents more effective with inferior fundus. ${ }^{9}$

In the absence of PVR, silicone oil has been clearly shown to be "adequate" for providing simultaneous support of superior and inferior fundus; the best example of this is its use in macular translocation with $360^{\circ}$ retinotomy. ${ }^{10-12}$ In these cases, preoperatively there is no RD or PVR. The use of endolaser and silicone oil alone is quite successful at re-attaching the retina without scleral buckle. Similarly, Tanner et al have shown that the use of vitrectomy and gas can be successful at repairing rhegmatogenous RD arising from inferior retinal breaks without buckles being applied..$^{13}$

In cases of PVR, ERM formation and recurrent RD are associated with seen or unseen retinal breaks in the inferior retina. ${ }^{14}$ We are persuaded that there is a case for using a heavier than water tamponade agent to treat cases with inferior retinal breaks associated PVR and especially in cases of recurrent RD after the use of gas or with silicone oil in situ.

The anatomical and functional results were satisfactory. Most significantly, no patients developed macula off detachments once Densiron was used, even though a proportion had subsequent re-operations involving gas or silicone oil injection. Re-attachment with one operation using Densiron was $81 \%$ (34 of 42 ) and with further operations was 93\% (39 of 42 ). At the end of the study, Densiron was removed from all patients and silicone oil remained in situ in four of 42 patients. Success rate according to our end point-that is, total re-attachment without any tamponade was $86 \%$ (36 of 42). These results seemed to be better than those of Oxane$\mathrm{Hd}$ (Bausch and Lomb). ${ }^{15}$ This is probably because Oxane-Hd 
was used to treated cases with more severe PVR. It might also be that Oxane-Hd is too light $\left(1.02 \mathrm{~g} / \mathrm{cm}^{3}\right)$, a conclusion that we reached from model chamber measurements. ${ }^{1}$

We previously reported the inflammatory reaction of $\mathrm{F}_{6} \mathrm{H}_{8}$ and speculated that it was due partly to its propensity to disperse. ${ }^{16}$ By dissolving it in $5000 \mathrm{mPas}$ silicone oil the viscosity of $\mathrm{F}_{6} \mathrm{H}_{8}$ was increased from $2.5 \mathrm{mPas}$ to $1387 \mathrm{mPas}$, thus the readiness to disperse was greatly reduced. In this study, we did not observe clinically significant dispersion nor did we find any inflammation more than we would expect from routine vitreoretinal surgery. Excessive inflammation was however observed with Oxane- $\mathrm{Hd},{ }^{6}$ which has a viscosity of over $3000 \mathrm{mPas}$. The proportion of $\mathrm{F}_{6} \mathrm{H}_{8}$ in silicone oil is well within its solubility within a wide range of ambient temperatures. This may be an important factor in its biocompatibility.

We believe that the availability of Densiron may add to our repertoire in managing selected $\mathrm{RD}$. This study does not address whether Densiron is more or less effective than conventional silicone oil; the multicentred "Heavy Silicone Oil" Study is now under way with the lead centre based in Cologne, Germany.

\section{Authors' affiliations}

D Wong, T Stappler, C Groenewald, I A Pearce, J N McGalliard*, E Manousakis, E N Herbert, St Paul's Eye Unit, Royal Liverpool University Hospital, Prescot Street, Liverpool L7 8XP, UK J C Van Meurs, The Rotterdam Eye Hospital, Schiedamsevest 180, 3011 $\mathrm{BH}$, Rotterdam, Netherlands

*Deceased.

The authors have no financial interest in the product Densiron.

Correspondence to: Mr David Wong, St Paul's Eye Unit, Royal Liverpool University Hospital, Prescot Street, Liverpool L7 8XP, UK; shdwong@liv. ac.uk

Accepted for publication 7 September 2004

\section{REFERENCES}

1 Wetterqvist C, Wong D, Williams R, et al. Tamponade efficiency of perfluorohexyloctane and silicone oil solutions in a model eye chamber. Br J Ophthalmol 2004;88:692-6.

2 Kirchhof B, Wong D, Van_Meurs J, et al. Use of perfluorohexyloctane as a long-term internal tamponade agent in complicated retinal detachment surgery. Am J Ophthalmol 2002;133:95-101

3 De_Molfetta V, Bottoni F, Arpa P, et al. The effect of simultaneous internal tamponade on fluid compartmentalization and its relationship to cell proliferation. Retina 1992;12(Suppl 3):S40-5.

4 Kertes P, Wafapoor H, Peyman G, et al. The management of giant retinal tears using perfluoroperhydrophenanthrene. A multicenter case series. Vitreon Collaborative Study Group. Ophthalmology 1997; 104:1 159-65.

5 Bottoni F, Arpa P, Vinciguerra P, et al. Combined silicone and fluorosilicone oil tamponade (double filling) in the management of complicated retinal detachment. Ophthalmologica. Journal International D\&\#034;Ophtalmologie. Int J Ophthalmol, Zeitschrift Fur Augenheilkunde 1992;204:77-81.

6 Theelen T, Tilanus M, Klevering B. Intraocular inflammation following endotamponade with high-density silicone oil. Graefes Arch Clin Exp Ophthalmol 2004

7 Gremillion C Jr, Peyman G, Liu K, et al. Fluorosilicone oil in the treatment of retinal detachment. Br J Ophthalmol 1990;74:643-6.

8 Fawcett IM, Williams RL, Wong D. Contact angles of substances used for internal tamponade in retinal detachment surgery. Graefes Arch Clin Exp Ophthalmol 1994;232:438-44

9 Wong D, Stappler T, Williams R. Sinking filling. Ophthalmo-Chirurgie 2004:16:147-50.

10 Wong $D$, Stanga $P$, Briggs $M$, et al. Case selection in macular relocation surgery for age related macular degeneration. $\mathrm{Br} J$ Ophthalmol 2004;88: 186-90.

11 Eckardt C, Eckardt U, Conrad HG. Macular rotation with and without counterrotation of the globe in patients with age-related macular degeneration. Graefes Arch Clin Exp Ophthalmol 1999;237:313-25.

12 Pertile G, Claes C. Macular translocation with 360 degree retinotomy for management of age-related macular degeneration with subfoveal choroida neovascularization. Am J Ophthalmol 2002;134:560-5.

13 Tanner V, Minihan M, Williamson TH. Management of inferior retinal breaks during pars plana vitrectomy for retinal detachment. $\mathrm{Br} J$ Ophthalmol 2001;85:480-2.

14 Singh A, Glaser B, Lemor M, et al. Gravity-dependent distribution of retinal pigment epithelial cells dispersed into the vitreous cavity. Retina 1986:6:77-80

15 Wolf S, Schon V, Meier P, et al. Silicone oil-RMN3 mixture ("heavy silicone oil") as internal tamponade for complicated retinal detachment. Retina 2003;23:335-42

16 Hiscott P, Magee RM, Colthurst M, et al. Clinicopathological correlation of epiretinal membranes and posterior lens opacification following perfluorohexyloctane tamponade. Br J Ophthalmol 2001;85:179-83. 